\title{
Immune-related redox metabolism of embryonic cells of the tick Rhipicephalus microplus (BME26) in response to infection with Anaplasma marginale
}

Sandra Patricia Kalil', Rafael Diego da Rosa ${ }^{1,3}$, Janaína Capelli-Peixoto ${ }^{1}$, Paula Cristiane Pohl', Pedro Lagerblad de Oliveira ${ }^{2}$, Andrea Cristina Fogaça ${ }^{1}$ and Sirlei Daffre ${ }^{1 *}$

\begin{abstract}
Background: It is well known that reactive oxygen species (ROS) and reactive nitrogen species (RNS) are involved in the control of pathogens and microbiota in insects. However, the knowledge of the role of ROS and RNS in tickpathogen and tick-microbiota interactions is limited. Here, we evaluated the immune-related redox metabolism of the embryonic cell line BME26 from the cattle tick Rhipicephalus microplus in response to Anaplasma marginale infection.

Methods: A high-throughput qPCR approach was used to determine the expression profile of 16 genes encoding proteins involved in either production or detoxification of ROS and RNS in response to different microbial challenges. In addition, the effect of RNAi-mediated gene silencing of catalase, glutathione peroxidase, thioredoxin and protein oxidation resistance 1 in the control of infection with $A$. marginale was evaluated.

Results: Infection with A. marginale resulted in downregulation of the genes encoding ROS-generating enzymes dual oxidase and endoplasmic reticulum oxidase. In contrast, the genes encoding the antioxidant enzymes superoxide dismutase, catalase, glutathione peroxidase, glutathione S-transferase, thioredoxin, thioredoxin reductase and peroxiredoxin were upregulated. The gene expression pattern in response to infection with Rickettsia rickettsii and exposure to heat-killed microorganisms, Micrococcus luteus, Enterobacter cloacae or S. cerevisiae was the opposite of that triggered by A. marginale challenge. The simultaneous silencing of three genes, catalase, glutathione peroxidase, and thioredoxin as well as the oxidation resistance 1 gene by RNAi apparently favoured the colonization of BME26 cells by A. marginale, suggesting that the antioxidant response might play a role in the control of infection.

Conclusions: Taken together, our results suggest that a general response of tick cells upon microbial stimuli is to increase ROS/RNS production. In contrast, A. marginale infection triggers an opposite profile, suggesting that this pathogen might manipulate the tick redox metabolism to evade the deleterious effect of the oxidant-based innate immune response.
\end{abstract}

Keywords: Anaplasmosis, Redox metabolism, Rickettsiae, Tick immunity, ROS

\footnotetext{
* Correspondence: sidaffre@icb.usp.br

'Department of Parasitology, Institute of Biomedical Sciences, University of

São Paulo, São Paulo, São Paulo 05508-900, Brazil

Full list of author information is available at the end of the article
} 


\section{Background}

Reactive oxygen species (ROS) are highly reactive oxygen-derived molecules with the potential to damage key cellular components, including lipids, proteins, and DNA. ROS also have an essential role in infectionrelated physiological and pathophysiological processes such as signalling, control of tissue injury and inflammation, as well as cell survival, proliferation, differentiation, and apoptosis $[1,2]$. In the immune response to pathogens, ROS and reactive nitrogen species (RNS) are rapidly generated by specific enzymes in many cell types. These enzymes include NADPH oxidase, which produces superoxide anion $\left(\mathrm{O}_{2}^{-}\right)$; dual oxidase (DUOX) and endoplasmic reticulum oxidoreductin (ERO1), which produce hydrogen peroxide $\left(\mathrm{H}_{2} \mathrm{O}_{2}\right)$; and nitric oxide synthase (NOS), which generates nitric oxide (NO) [3-5]. Cells have developed strategies to counteract the potential damage of ROS via detoxification of these molecules and repair of damage induced by ROS. In this respect, superoxide dismutase (SOD) converts $\mathrm{O}_{2}^{-}$ into $\mathrm{H}_{2} \mathrm{O}_{2}$ whereas catalase (CAT) and glutathione peroxidase (GPX) detoxify $\mathrm{H}_{2} \mathrm{O}_{2}$ into $\mathrm{H}_{2} \mathrm{O}$ and $\mathrm{O}_{2}$ [6]. Thioredoxins (TRX), which are a partner of reduced/oxidized glutathione in redox regulation, catalyze the reversible reduction of protein disulphide bonds, while the cysteine residues of TRX active-site are reduced by both TRX reductase (TRXR) and NADPH [7]. Peroxiredoxins (PRX) are a group of non-seleno thiol-specific peroxidases that contribute to cellular redox control by eliminating organic hydroperoxides and $\mathrm{H}_{2} \mathrm{O}_{2}$. In addition, phospholipid hydroperoxide glutathione peroxidases (PHGPX) catalyze the reduction of $\mathrm{H}_{2} \mathrm{O}_{2}$ using glutathione as an electron donor [8]. Finally, glutathione S-transferases (GST) catalyze the conjugation of GSH and electrophilic compounds, increasing the solubility of products and facilitating their excretion [9].

In arthropods, the triggering of ROS/RNS production is a key component of the response to pathogens [10-13]. In the midgut of Drosophila, DUOX is essential to control the number of pathogenic microorganisms [10]. In the midgut of Anopheles gambiae, infection with Plasmodium berghei decreased $\mathrm{H}_{2} \mathrm{O}_{2}$ detoxification, which limits parasite survival, suggesting that ROS is involved in modulating mosquito immunity [13]. The same research group showed that silencing the gene encoding the protein oxidation resistance 1 (OXR1) increased the systemic levels of $\mathrm{H}_{2} \mathrm{O}_{2}$ and consequently decreased $P$. berghei infection [11]. In mosquitoes, it has also been shown that DUOX, together with a heme-peroxidase, promotes the formation of a dityrosine bond between extracellular proteins, forming a network that prevents immune activation by the gut microbiota [12].

The process of redox-based innate immune effectors in response to pathogen infection is much less understood in ticks. Our research group demonstrated that $\mathrm{O}_{2}^{-}$and $\mathrm{H}_{2} \mathrm{O}_{2}$ were produced by the hemocytes of the cattle tick Rhipicephalus microplus in response to a microbial challenge with Micrococcus luteus, zymosan, and phorbol 12-miristate 13-acetate (PMA) [14]. Moreover, analogous to what had been described for the mosquitoes, Yang et al. [15] suggested that DUOX/peroxidase system is important for the survival of Borrelia burgdorferi in the gut of the tick Ixodes scapularis. Similar to the results observed for mosquitoes [12], the silencing of either DUOX or peroxidase impaired the acellular gut barrier formed by tyrosine cross-linking (dityrosine) and thus reduced the load of $B$. burgdorferi in the tick gut. Importantly, the induction of NOS gene expression and activity by disruption of the dityrosine network promoted a decrease of bacterial load [15].

Our research group is interested in understanding the immune response of $R$. microplus during infection with Anaplasma marginale, the etiological agent of bovine anaplasmosis. This disease causes significant economic losses due to temporary infertility, abortion, increased mortality, and high costs of treatment [16]. We have previously reported significant differences in the transcriptional expression profile of genes encoding components of tick immune signaling pathways (Toll, IMD, JNK, and Jak-Stat) in non-infected BME26 cells (derived from $R$. microplus embryos) in comparison to cells harboring either $A$. marginale or Rickettsia rickettsii, the causative agent of Rocky Mountain spotted fever [17]. Most of the analyzed genes were downregulated by $A$. marginale infection, suggesting that this pathogen might manipulate the tick immune system, favouring bacterial survival and colonization. In contrast, the expression of most of the genes from immune signalling pathways in $R$. rickettsii-infected cells was upregulated. Moreover, another study of our group revealed that the IMD signalling pathway controls $A$. marginale infection in adult male $R$. microplus ticks [18].

Here, we assessed the role of immune-related redox metabolism in the control of $A$. marginale infection in BME26 cells. First, we determined the differential expression profile of redox metabolism genes in BME26 cells exposed to microbial stimuli, including two alive pathogens naturally transmitted by ticks, $A$. marginale and $R$. rickettsii, and three heat-killed microorganisms not transmitted by ticks (M. luteus, Enterobacter cloacae and Saccharomyces cerevisiae). Differently, from other microbial stimuli, $A$. marginale infection upregulated the majority of antioxidant genes while most of the prooxidant genes were downregulated. In addition, the silencing of the genes encoding proteins involved in ROS detoxification, catalase, glutathione peroxidase, thioredoxin and oxidation resistance 1 by RNAi decreased the load of A. marginale in BME26 cells. These results 
suggest that $A$. marginale might manipulate the tick redox mechanism favouring its survive. However, it cannot be ruled out that host cell response controls infection.

\section{Methods}

Tick cell lines and microorganisms

The embryonic cell lines BME26, derived from $R$. microplus [19], and ISE6, derived from I. scapularis [20], were cultured as previously described [19]. Cell growth and viability were assessed by cell counting in a Neubauer chamber using optical microscopy after trypan blue staining. The microorganisms used in the experiments were the Gram-positive bacterium Micrococcus luteus (ATCC 9341A), the Gram-negative bacterium Enterobacter cloacae K12 (provided by Dr Hans G. Boman, Stockholm University, Sweden), the yeast Saccharomyces cerevisiae (ATCC 208353) and the rickettsiae Anaplasma marginale (Jaboticabal strain) [21] and Rickettsia rickettsii (Taiaçu strain) [22].

\section{Nucleic acid extraction and CDNA synthesis}

Total RNA and genomic DNA (gDNA) were extracted from BME26 cells using TRIzol ${ }^{\circ}$ reagent (Thermo Fisher Scientific, Waltham, USA) and Smarter Nucleic Acid Sample Preparation (STRATEC Molecular, Berlin, Germany), respectively, as described previously [17]. RNA samples were treated with DNase I (Thermo Fisher Scientific) to eliminate contaminant gDNA, and cDNA was synthesized using 250-1000 ng of purified total RNA as template in a $20 \mu \mathrm{l}$ reaction volume containing $2.5 \mu \mathrm{M}$ oligo $(\mathrm{dT}), 0.5 \mathrm{mM}$ dNTPs, $5 \mathrm{mM}$ DTT, 2 units of RNaseOUT ribonuclease inhibitor (Thermo Fisher Scientific), and 10 units of SuperScript III reverse transcriptase (Thermo Fisher Scientific), according to the manufacturer's instruction. As a control, an aliquot of treated RNA was used in PCR reactions to confirm the elimination of residual genomic DNA (data not shown).

\section{Quantification of $A$. marginale and $R$. rickettsii by real-time quantitative PCR}

The number of rickettsiae in BME26 cells was determined by quantitative real-time PCR (qPCR) using specific primers and a hydrolysis probe for the genes that encode the major surface protein 5 (msp5) of $A$. marginale [23] and citrate synthase of $R$. rickettsii ( $g l t A$ ) [24]. Briefly, the amplification reaction was performed in three technical replicates in a final volume of $15 \mu \mathrm{l}$ containing $2 \mu \mathrm{l}$ of gDNA (approximately $100 \mathrm{ng}$ ), $2 \mu \mathrm{l}$ of a mixture of forward and reverse primers $(0.6 \mu \mathrm{M}$ each), $0.02 \mu \mathrm{l}$ of TaqMan probe, $7.5 \mu \mathrm{l}$ of Maxima Probe/ROX qPCR Master Mix (Thermo Fisher Scientific), and $3.5 \mu \mathrm{l}$ of ultrapure water. The reactions were performed on a StepOnePlus $^{\text {Tw }}$ Real-Time PCR System (Thermo Fisher
Scientific) using the following thermocycler programs: $10 \mathrm{~min}$ at $95{ }^{\circ} \mathrm{C}$, followed by 40 cycles of $15 \mathrm{~s}$ at $95{ }^{\circ} \mathrm{C}$, $30 \mathrm{~s}$ at $60{ }^{\circ} \mathrm{C}$, and $45 \mathrm{~s}$ at $72{ }^{\circ} \mathrm{C}($ A. marginale) and $10 \mathrm{~min}$ at $95{ }^{\circ} \mathrm{C}$, followed by 40 cycles of $15 \mathrm{~s}$ at $95{ }^{\circ} \mathrm{C}$, $15 \mathrm{~s}$ at $55{ }^{\circ} \mathrm{C}$, and $30 \mathrm{~s}$ at $72{ }^{\circ} \mathrm{C}(R$. rickettsii). In each analysis, the cycle of quantification $\left(C_{\mathrm{q}}\right)$ values of reactions using a dilution series of $10^{2}$ to $10^{7}$ copies of a plasmid (pGEM- ${ }^{\circ} \mathrm{T}$ Easy, Promega, Madison, USA) containing a fragment of either $m s p 5$ or $g l t A$ were used to establish a standard curve for determining the absolute number of $A$. marginale and $R$. rickettsii, respectively. To that end, those fragments were previously sequenced to confirm their identity to respective sequences in public databases.

\section{Primers}

The primer design for the high-throughput microfluidic RT-qPCR assay was made manually, and the parameters included a primer annealing temperature of $58{ }^{\circ} \mathrm{C}$ to $62{ }^{\circ} \mathrm{C}$, primer length of 20 to $21 \mathrm{bp}$, primer G/C content of approximately 50\%, and amplicon length of 100-200 bp. Potential self-complementarity and primer-dimer formation were checked using FastPCR Professional software (http://primerdigital.com/fastpcr.html). The efficiency of primers used in RT-qPCR was calculated in the BioMark Real-Time PCR System, and only primers with an amplification efficiency above 90 (linear $C_{q}$ values) were accepted. All primers used in this study are fully detailed in Additional file 1.

\section{High-throughput microfluidic RT-qPCR}

The microbial stimuli of BME26 cells, extraction of nucleic acids, high-throughput microfluidic RT-qPCR, and data analysis were performed simultaneously to the previously study of our research group [17]. As recognized by the Minimum Information for Publication of Quantitative Real-Time PCR Experiments, the MIQE Guidelines [25], the expression of different candidate genes for RT-qPCR data normalization was examined. In our analysis, eight candidate genes were considered: elongation factor-1 alpha $(e f-1 \alpha)$, glyceraldehyde-3phosphate dehydrogenase (gapdh), beta-actin (actb), malate dehydrogenase $(m d h)$, glutamate dehydrogenase ( $g d h)$, cytochrome $c$ oxidoreductase (cypor), 40S ribosomal protein S3A (RIBS3A) and ribosomal protein L4 (rpl4). Their expression levels were analyzed individually $\left(C_{q}\right.$ values) and in combination (geometric mean of $C_{q}$ values) [26]. For our experimental conditions, the best reference for qPCR normalization in BME26 cells was the geometric mean of the $\mathrm{C}_{\mathrm{q}}$ values of $m d h$, gdh, cypor and $40 S R P S 3 A$ regarding both $\mathrm{C}_{\mathrm{q}}$ variation and primer efficiency. 


\section{RNAi gene-silencing assay}

To verify the importance of an antioxidant response of BME26 cells on A. marginale infection, the encoding genes of catalase (GenBank: CV451339), gpx (GenBank: CV440147), trxr (GenBank: CV451339) and oxr1 (GenBank: MF503617) were silenced using RNA-mediated interference (RNAi). The encoding gene of the merozoite surface protein 1 ( $m s p 1)$ of Plasmodium falciparum was used as control (GenBank: AF061132). Target DNA fragments were amplified using cDNA from BME26 cells or a plasmid containing $m s p 1$ and primers designed for Rmcat, Rmgpx, Rmtrxr, Rm oxr1, or Pfmsp1 containing the T7 polymerase promoter sequence (Additional file 1: Table S1). The PCR cycling conditions were: $95{ }^{\circ} \mathrm{C}$ for $30 \mathrm{~s}$ followed by 30 cycles of $55{ }^{\circ} \mathrm{C}$ for $1 \mathrm{~min}$ and $72{ }^{\circ} \mathrm{C}$ for $1 \mathrm{~min}$. PCR products were analyzed by agarose gel electrophoresis and purified using the GeneJet Purification kit (Fermentas, Vilnius, Lithuania). dsRNAs were synthesized using the T7 RiboMax $^{\mathrm{Tm}}$ Express RNAi System kit (Promega) and $950 \mathrm{ng}$ of PCR-amplified DNA fragments as template. After dsRNA synthesis, the specificity was checked by electrophoresis in agar gel. Only dsRNA with a unique band with the expected size were used.

BME26 cells $\left(1.5 \times 10^{6}\right)$ were sub-cultured into flasks for $24 \mathrm{~h}$ before the addition of $10^{13}$ dsRNA molecules in L15B infection medium [27]. The BME26 cells were incubated simultaneously with a mixture of dscat, dsgpx, and dstrxr, or dsoxr1 alone; $\mathrm{d} s m s p 1$ was used as a control. After $24 \mathrm{~h}$, BME26 cells were challenged with $A$. marginale. To that end, frozen cultures of $A$. marginale in ISE6 cells were used $\left(3 \times 10^{8}\right.$ bacteria/vial) were thoroughly lysed by subjecting the samples to three cycles of freezing in liquid nitrogen followed by thawing in a waterbath at $37{ }^{\circ} \mathrm{C}$. Then, the suspension was centrifuged at $500 \times g$ for $5 \mathrm{~min}$ at $4{ }^{\circ} \mathrm{C}$, and the same volume of supernatant was added as inoculum in all experiments. An aliquot of the inoculum was stored for quantification of bacteria along with the aliquots collected from each time point. The quantification of the inoculum was further used to calculate the rickettsiae infection ratio of each experiment. Therefore, ratios may vary among assays from 1:9 to 1:90. After incubation for additional $72 \mathrm{~h}$, the supernatant was discarded, the cell monolayer was washed with PBS and then detached with a scraper or Trypsin-EDTA solution (Vitrocell, Campinas, Brazil). The cell suspension was centrifuged at $3000 \times g$ for $10 \mathrm{~min}$ at $4{ }^{\circ} \mathrm{C}$. RNA and gDNA were extracted from resulting pellet and used for evaluation of gene silencing and bacterial quantification, respectively. The expression of target genes (cat, gpx, trxr, oxr1) and the endogenous reference gene (40S ribosomal protein $S 3 a$ ) was assessed by SYBR green quantitative real-time PCR (qPCR). The reactions were performed on a StepOnePlus $^{\text {TM }}$ Real-Time PCR System (Thermo Fisher Scientific). The PCR condition was $95{ }^{\circ} \mathrm{C}$ for $10 \mathrm{~min}$ followed by 40 cycles of $95{ }^{\circ} \mathrm{C}$ for $15 \mathrm{~s}$ and $60{ }^{\circ} \mathrm{C}$ for $1 \mathrm{~min}$. Gene expression was analyzed as described for the high-throughput microfluidic RT-qPCR experiment [17]. The number of $A$. marginale in BME26 cells was determined by qPCR. Five and eight biological replicates (flasks of BME26 cells) were processed for each group (treated with either control or target gene dsRNA) in the triple and oxr1 silencing experiments, respectively. The infection ratio was 1:9 (triple silencing) and 1:64 (oxr1 silencing).

\section{Quantitation of $\mathrm{H}_{2} \mathrm{O}_{2}$}

$\mathrm{H}_{2} \mathrm{O}_{2}$ was measured with Amplex Red (Invitrogen) following the recommendations of the manufacturer (Amplex ${ }^{\oplus}$ Red Hydrogen Peroxide/Peroxidase Assay Kit, Thermo Fisher Scientific). Before the bacterial challenge, $5 \times 10^{4}$ BME26 cells were sub-cultured in 24-well plates for $24 \mathrm{~h}$ followed by two washes with Krebs-Ringer phosphate buffer with glucose (KRPG) (145 $\mathrm{mM} \mathrm{NaCl}, 5.7 \mathrm{mM}$ sodium phosphate, $4.86 \mathrm{mM} \mathrm{KCl}, 0.54 \mathrm{mM} \mathrm{CaCl}, 1.22 \mathrm{mM} \mathrm{MgSO}_{4}$, $5.5 \mathrm{mM}$ glucose, $\mathrm{pH}$ 7.35) and incubation in KRPG containing $100 \mu \mathrm{M}$ Amplex Red (10-acetyl-3,7-dihydroxyphenoxazine) and $0.2 \mathrm{U} / \mathrm{ml}$ horseradish peroxidase (HRP). Tick cells were challenged with $A$. marginale (ratio 1:34) obtained as described above (RNAi gene-silencing assay). Uninfected ISE6 cell lysate prepared as described for $A$. marginale inoculum was used as a control. In addition, BME26 cells incubated with $125 \mu \mathrm{M}$ menadione served as the positive control $[28,29]$. At $1,6,24$ and 72 h postchallenge at $34{ }^{\circ} \mathrm{C}$ in the dark, the incubation medium was centrifuged for $2 \mathrm{~min}$ at $10000 \times \mathrm{g}$, and the supernatant was transferred to cell culture plates (Corning Costar ${ }^{\oplus}$; CLS3991, Sigma-Aldrich). The fluorescence was measured using a SpectraMax 190 (Molecular Devices, Sunnyvale, USA) with excitation at $560 \mathrm{~nm}$ and emission at $590 \mathrm{~nm}$ and was compared to a standard curve containing 0.05 to 500 pmol of $\mathrm{H}_{2} \mathrm{O}_{2}$. Three biological samples were analyzed for each treatment.

\section{Statistical analysis}

The differences between treatments were analyzed statistically by Mann-Whitney test using GraphPad Prism version 7.0 for Windows (GraphPad Software, San Diego, CA, USA). A P-value lower than 0.05 was considered statistically significant. 


\section{Results}

Redox balance genes are differentially expressed in BME26 cells upon microbial stimuli

First, we evaluated $A$. marginale and $R$. rickettsii growth in BME26 cells and the cell viability along infection (Table 1). The infection ratios with rickettsiae were based on the kinetics of growth previously standardized by our research group. As $R$. rickettsii grows faster than A. marginale and it is quite more virulent, causing the death of the tick cells, we used an inoculum approximately $10^{4}$ lower of $R$. rickettsii than of $A$. marginale. The total number of $A$. marginale remained relatively constant (average of $5.57 \times 10^{7}$ rickettsiae/flask) over the $72 \mathrm{~h}$ infection period, and the mortality rate of BME26 cells was low (less than 20\%). In contrast, the average number of $R$. rickettsii increased during infection and reached $1.61 \times 10^{6}$ bacteria/flask over $48-$ $72 \mathrm{~h}$ post-infection. $R$. rickettsii counts in BME26 cells were below the detection threshold of the absolute quantification by qPCR at 6 and 24 h (Table 1 ). Although no significant differences in the number of R. rickettsii were found between 48 and $72 \mathrm{~h}$, the mortality of BME26 cells reached approximately $45 \%$ at $72 \mathrm{~h}$ post-infection. It is important to note that at $48 \mathrm{~h}$ and $72 \mathrm{~h}$ post-infection, the quantity of the two rickettsiae in BME26 cells differs by only one order of magnitude (Table 1).

The transcriptional analysis of BME26 cells was evaluated at 6, 24 and $72 \mathrm{~h}$ after experimental infection with either $A$. marginale or $R$. rickettsii or stimulation with heat-killed microorganisms (M. luteus, E. cloacae or $S$. cerevisiae). No microbial growth was observed after plating the heat-killed microorganisms in an appropriate medium. The results revealed a remarkable difference in the expression of redox metabolism genes in BME26 cells experimentally infected with $A$. marginale compared with the other microbial stimuli (Fig. 1). During $A$. marginale infection, most of the pro-oxidant genes were downregulated, except for $R m N O S$, which was upregulated at 6 and $72 \mathrm{~h}$ post-infection. However, most antioxidant genes were upregulated along the infection. It is known that redox equilibrium is modulated in the gut of Aedes aegypti after a blood meal [30]. For this reason, we analyzed the relative gene expression in BME26 cells incubated with blood cell debris versus PBS (Fig. 1). The upregulation of the vast majority of pro-oxidant genes and downregulation or non-modulation of most antioxidant genes was observed along the $72 \mathrm{~h}$ of stimulation. It is of note that this profile is opposite to that observed in BME26 cells infected with the inoculum of A. marginale harboured in blood cells. The global analysis of gene expression of BME26 cells in response to $R$. rickettsii challenge showed that most antioxidant genes were downregulated along infection compared with $A$. marginale, while all pro-oxidant genes were upregulated in at least one point postinfection (Fig. 1). After $72 \mathrm{~h}$, all evaluated antioxidant genes were upregulated by $A$. marginale infection, whereas some of these genes were down-regulated by R. rickettsii.

The results of the stimulus of BME26 cells with heat-killed microorganisms (M. luteus, E. cloacae and $S$. cerevisiae) showed that the expression of most prooxidant genes was upregulated and the expression of many antioxidant genes was down-regulated. Although the expression pattern of BME26 cells in response to the heat-killed microorganism is similar, this profile is different from that observed for infection with alive $A$. marginale (Fig. 1).

\section{Anaplasma marginale infection is limited by the simultaneous silencing of Rmcat, Rmgpx, Rmtrxr or by Rmoxr 1 in BME26 cells}

As A. marginale triggered an antioxidant profile in BME26 cells, the effect of the simultaneous silencing of three antioxidant genes in tick cells, Rmcat, Rmgpx and Rmtrxr, on infection was determined. For this purpose, BME26 cells were incubated at the same time with specific dscat, dsgpx, and dstrxr and then infected with $A$. marginale. The mRNA levels of Rmcat, Rmgpx, and Rmtrxr were $94.1 \%, 95.8 \%$ and $90.6 \%$ lower than the control group (dsmsp1) (Fig. 2a-c). In addition, a significant decrease in the number of bacteria was observed (Fig. 2d). Likewise, the Rmoxr1 silencing (37.5\%) (Fig. 3a) resulted in a significant reduction in infection levels of A. marginale (Fig. 3b). These results showed that

Table 1 Rickettsial quantification in BME26 cells

\begin{tabular}{|c|c|c|c|c|}
\hline \multirow[t]{2}{*}{ Post-infection (h) } & \multicolumn{2}{|l|}{ A. marginate infection } & \multicolumn{2}{|l|}{ R. rickettsii infection } \\
\hline & Number of bacteria/flask & \% BME26 mortality & Number of bacteria/flask & \% BME26 mortality \\
\hline 6 & $4.21 \times 10^{7} \pm 1.15 \times 10^{7}$ & $10 \pm 2$ & nd & $4 \pm 0.8$ \\
\hline 24 & $6.66 \times 10^{7} \pm 6.39 \pm 10^{6}$ & $16 \pm 4$ & nd & $11 \pm 2$ \\
\hline 48 & $4.86 \times 10^{7} \pm 7.77 \times 10^{6}$ & $16 \pm 8$ & $2.04 \times 10^{6} \pm 4.32 \times 10^{5}$ & $7 \pm 3$ \\
\hline 72 & $6.55 \times 10^{7} \pm 2.38 \times 10^{7}$ & $19 \pm 6$ & $1.18 \times 10^{6} \pm 4.52 \times 10^{5}$ & $45 \pm 4$ \\
\hline
\end{tabular}

The infection of BME26 cells was monitored by absolute qPCR. The mortality of BME26 cells was monitored by trypan blue staining under light microscopy (adapted from Rosa et al. [17]). Abbreviation: $n d$, not detected by qPCR 


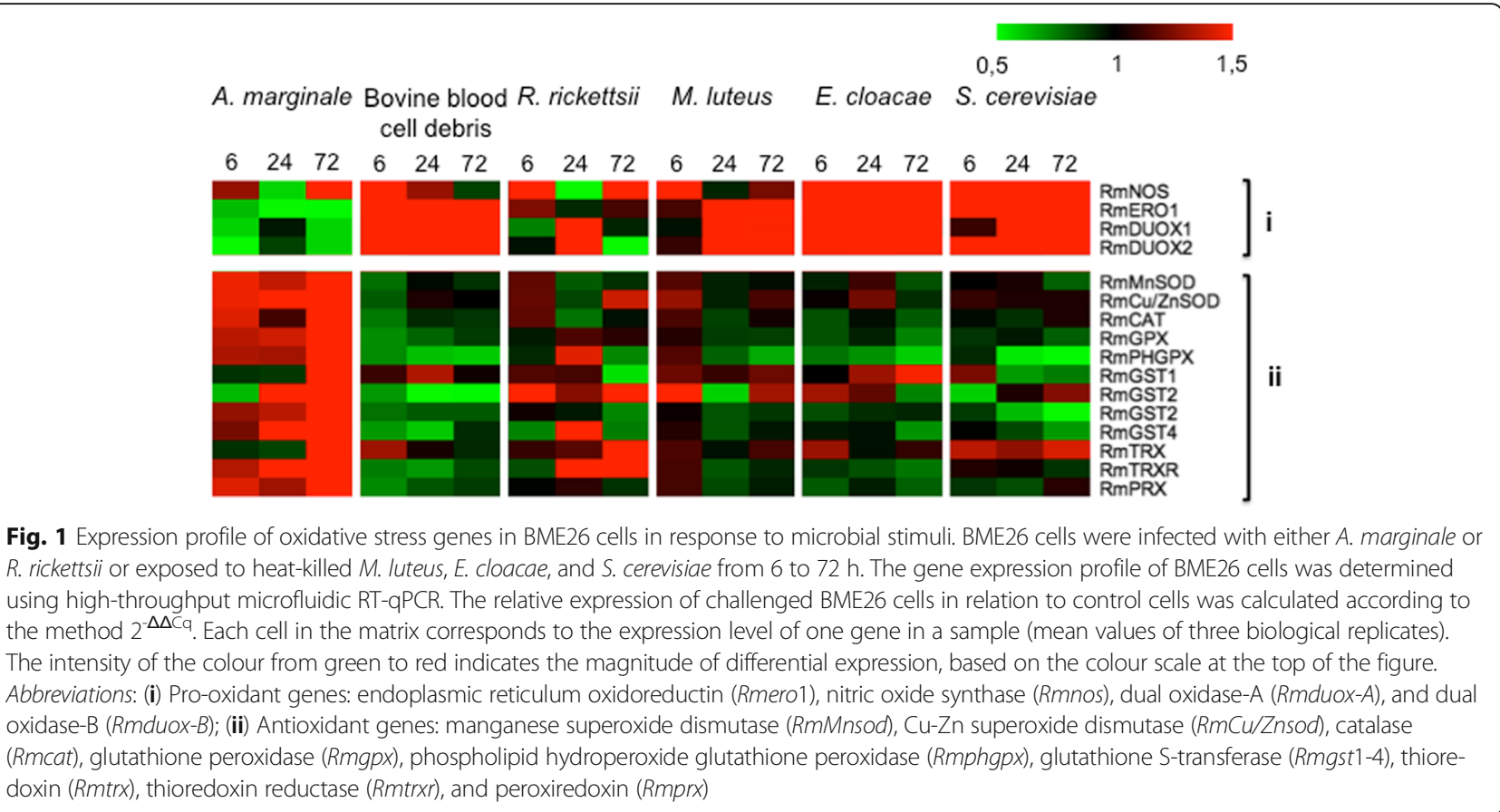

silencing of genes involved with antioxidant defence affects infection of BME26 cells by A. marginale.

\section{Quantification of $\mathrm{H}_{2} \mathrm{O}_{2}$ in BME26 cells infected with $A$. marginale}

Since genes involved with redox metabolism are modulated by $A$. marginale infection (Fig $1 \mathrm{~b}$ ), the quantity of $\mathrm{H}_{2} \mathrm{O}_{2}$ was evaluated in BME26 infected at 1, 6, 24 and $72 \mathrm{~h}$ (Fig. 4). There was no difference in the concentration of hydrogen peroxide produced by infected and noninfected cells at any experimental time points (Fig. 4). However, menadione stimulation, a known inducer of hydrogen peroxide production $[28,29]$, increased the production of $\mathrm{H}_{2} \mathrm{O}_{2}$, and the $\mathrm{H}_{2} \mathrm{O}_{2}$ levels varied between 250 and $350 \mathrm{pmol}$ in the studied time points.

\section{Discussion}

In many arthropod species, microbial recognition results in the activation of immune signalling pathways involved in the regulation of important immune-effectors, such as antimicrobial peptides [31]. Indeed, a previous study from our group using heat-killed microorganisms (M. luteus, $E$. cloacae and S. cerevisiae) showed that those microbial as stimuli elicited the modulation of many immune-related genes in BME26 cells [17]. Therefore, one of the aims of our study was to verify if those microorganisms could also modulate the expression of redox-related genes. In addition, to evaluate the expression of $R$. microplus redoxrelated genes during host-pathogen interactions, we have chosen two bacterial pathogens naturally transmitted by ticks, A. marginale and $R$. rickettsii. High-throughput
qPCR analysis demonstrated that distinct transcriptional patterns of redox metabolism genes are triggered in the cattle tick cell line BME26 in response to different microbial stimuli. Anaplasms marginale infection downregulated the expression of pro-oxidants genes and upregulated antioxidant genes. On the other hand, heatkilled microorganisms upregulated most of the prooxidant genes and downregulated pro-oxidant genes. Moreover, the gene expression profile induced by infection with $R$. rickettsii, which is not transmitted by the cattle tick, was an intermediary between $A$. marginale infection and the stimulation with heat-killed microorganisms. These results suggest that $A$. marginale infection subverted the host redox-based innate immune response by preventing the onset of an oxidative response, as elicited by the other microbial stimuli.

In accordance with these findings, in our previous study, we observed that $A$. marginale downregulates key components of the signalling immune pathways Toll, IMD, and Jak/Stat, which may reflect an attempt of this bacterium to manipulate the immune system of the host cells [17]. Despite the possible establishment of a favourable environment for the growth of $A$. marginale, we observed a relatively constant number of $A$. marginale over the $72 \mathrm{~h}$ infection period. The importance of the maintenance of an antioxidant environment by $A$. marginale was corroborated by either the simultaneous silencing of three antioxidant genes (Rmcat, Rmgpx and Rmtrxr) or Rmoxr 1 in tick cells, which led to a reduction in the number of bacteria. In turn, even though $R$. rickettsii induces an increase in the expression of most 

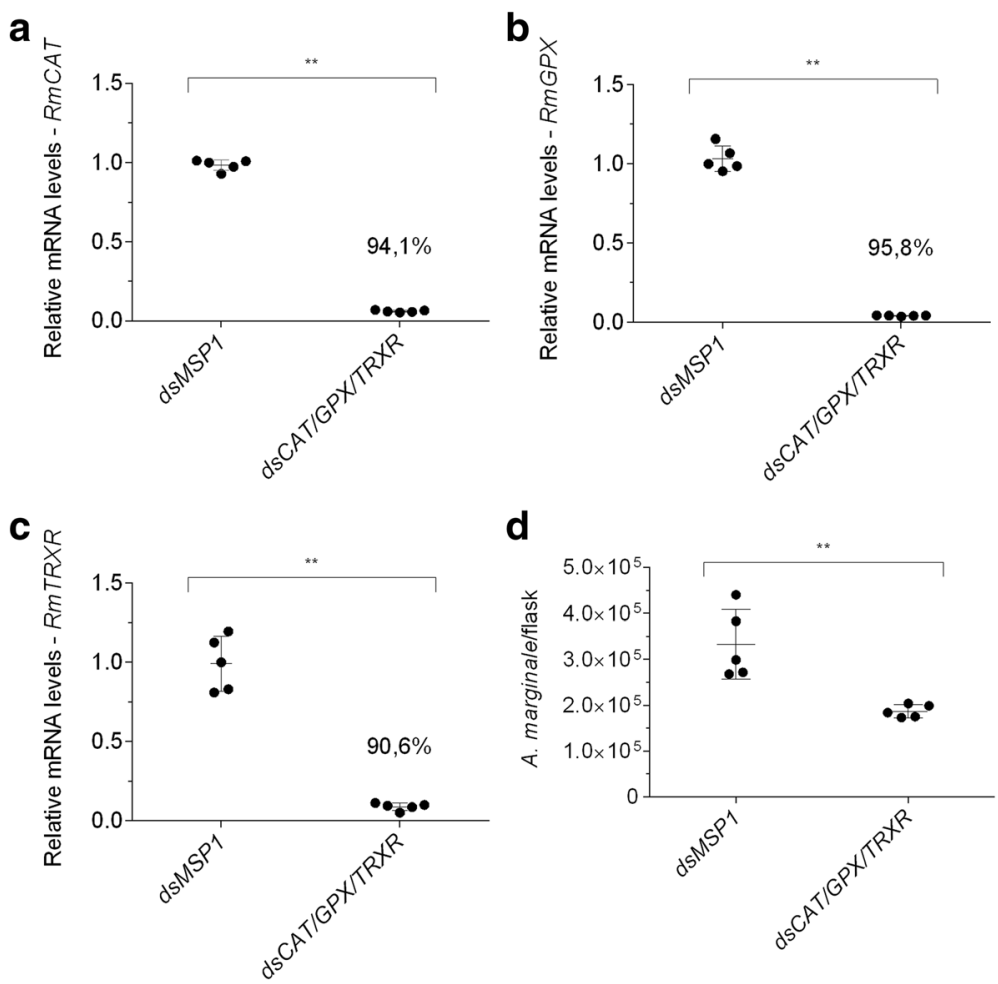

Fig. 2 Effect of RNAi-mediated silencing of Rmcat, Rmgpx and Rmtrxr in the control of infection of BME26 cells by Anaplasma marginale. BME26 cells were incubated simultaneously with Rmdscat, Rmdsgpx and Rmdstrxr, or with Pfdsmsp1 as a control for $24 \mathrm{~h}$ and then infected with $A$. marginale for $72 \mathrm{~h}$. The gene expression of BME26 cells was determined using RT-qPCR, and the number of $A$. marginale was determined using qPCR. Relative quantitation of the mRNA levels of Rmcat (a), Rmgpx (b) and Rmtrxr (c) in BME26 cells after incubation with dsRNAs compared with cells incubated with msp1 dsRNA (control). d Some A. marginale cells per flask at $72 \mathrm{~h}$ post-incubation in dsRNA-treated BME26 cells. The dots represent the relative mRNA levels or the number of $A$. marginale in individual flasks (five biological replicates), the horizontal line indicates the median relative mRNA level or the number of $A$. marginale cells, and bars represent the standard deviation at each time point. The percentage of gene silencing is indicated in $\mathbf{a}, \mathbf{b}$ and $\mathbf{c}$. The asterisk indicates significant differences by Mann-Whitney test $\left(U_{(10)}=0, Z=-2.88, P=0.0079\right)$
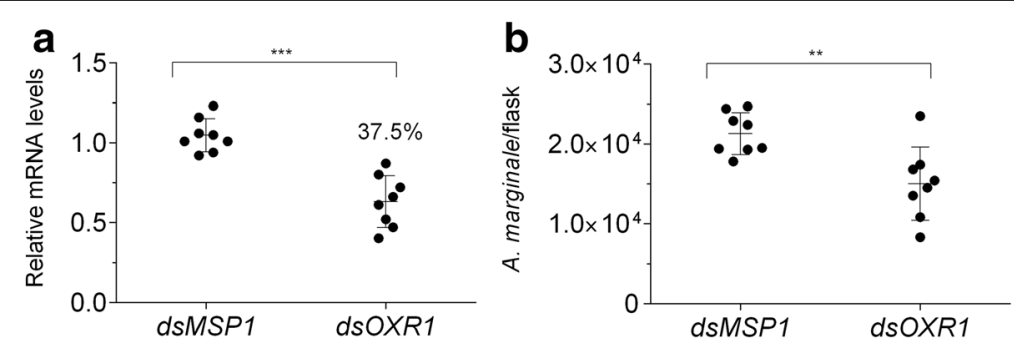

Fig. 3 Effect of RNAi-mediated silencing of Rmoxr1 in the control of infection of BME26 cells by Anaplasma marginale. BME26 cells were incubated with Rmds oxr1 or with Pfdsmsp1 as the control for $24 \mathrm{~h}$ and then infected with A. marginale for $72 \mathrm{~h}$. The gene expression of BME26 cells was determined using RT-qPCR, and the number of A. marginale was determined using qPCR. a Relative quantitation of the mRNA levels of Rmoxr1 in BME26 cells after incubation with dsRNAs compared with cells incubated with msp1 dsRNA (control). b A. marginale cells per flask at $72 \mathrm{~h}$ postincubation in dsRNA-treated BME26 cells. The dots represent the relative mRNA levels or the number of $A$. marginale in individual flasks (eight biological replicates), the horizontal line indicates the median relative mRNA level or the number of $A$. marginale cells, and bars represent the standard deviation. The percentage of gene silencing is indicated in $\mathrm{A}$. The asterisk indicates significant differences by Mann-Whitney test $\left(\mathbf{a} U_{(14)}=0, Z=-3.36, P=0.0002\right.$ and $\left.\mathbf{b} U_{(14)}=6, Z=-2.73, P=0.0047\right)$ 

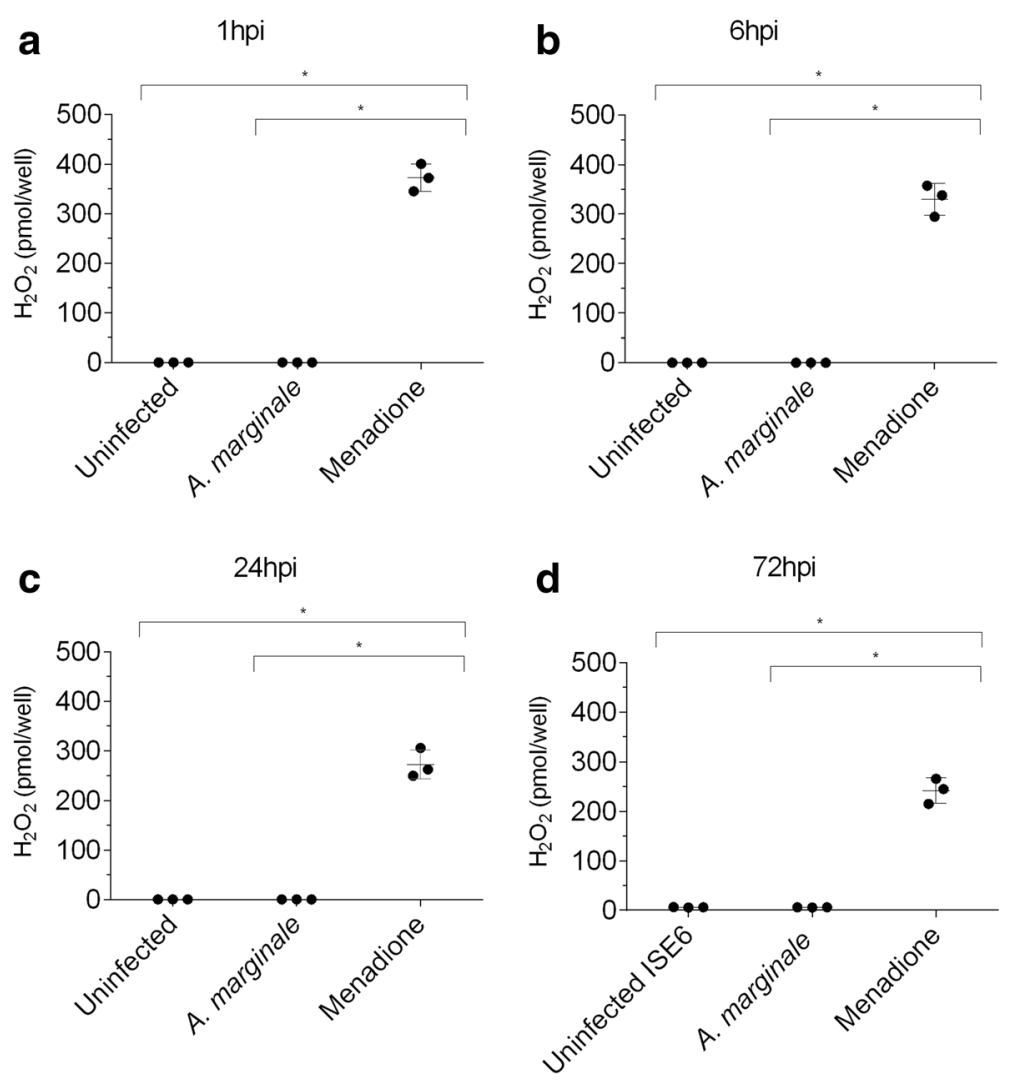

Fig. 4 Effect of Anaplasma marginale infection on $\mathrm{H}_{2} \mathrm{O}_{2}$ production by BME26 cells. BME26 cells were incubated with $\mathrm{A}$. marginale, menadione, or with uninfected tick cell lysate as control (uninfected). The $\mathrm{H}_{2} \mathrm{O}_{2}$ level in the supernatant was quantified using the Amplex Red assay at $1 \mathrm{~h}$ (a), $6 \mathrm{~h} \mathrm{(b),} 24 \mathrm{~h} \mathrm{(c)} \mathrm{and} 72 \mathrm{~h}$ (d) post-incubation. The dots represent the concentration of $\mathrm{H}_{2} \mathrm{O}_{2}$ in individual wells (three biological replicates), the horizontal line indicates the median concentration of $\mathrm{H}_{2} \mathrm{O}_{2}$ and bars represent the standard deviation at each time point. The asterisk indicates significant differences by Mann-Whitney test $\left(U_{(4)}=0, Z=-2.09, P=0.037\right)$

genes of the immune signaling pathways Toll, IMD, and Jak-Stat after $24 \mathrm{~h}$ of infection [17] and possibly creates a more pro-oxidant environment compared with $A$. marginale (RmDUOX-A and $R m D U O X-B$ were induced at $24 \mathrm{~h}$ post-infection), we observed high rates of $R$. rickettsii growth and mortality of BME26 cells. A previous study showed that antioxidant genes of $R$. rickettsii are upregulated in the midgut of its tick vector during the acquisition of the blood meal [32]. In addition, antioxidants genes of $R$. rickettsii are also upregulated in endothelial cells exposed to an oxidative environment [33, 34]. Upregulation of antioxidant genes might protect this bacterium against ROS, which may explain its significant growth rate in BME26 cells.

The microbicidal role of ROS produced by professional phagocytes in innate immunity of vertebrates is well known [35, 36]. In addition, it has been established that DUOX is involved in remodelling the intestinal microflora and elimination of unwanted microbes for the maintenance of the gut-microbe homeostasis of the fruit fly Drosophila melanogaster [37]. Another study demonstrated the involvement of ROS in mosquito immunity, which is important for the control of both bacteria and Plasmodium [13]. However, only a few studies have evaluated the role of ROS in microbial colonization in ticks. To that end, we quantified $\mathrm{H}_{2} \mathrm{O}_{2}$ at 1, 6, 24 and $72 \mathrm{~h}$ post-infection of BME2626 with $A$. marginale. It was not detected an augment of $\mathrm{H}_{2} \mathrm{O}_{2}$ production along the course of infection in relation to the control, in contrast to the observed with menadione (positive control). A hypothesis to explain this result is that $A$. marginale infection does not trigger an oxidative response in BME26 cells, which $w$ result in an increase in ROS production, such as $\mathrm{H}_{2} \mathrm{O}_{2}$. In fact, the expression of antioxidant genes was upregulated as early as six $\mathrm{h}$ post-infection with $A$. marginale, and their expression increased at $72 \mathrm{~h}$. However, future studies, such as the measure of the activity of antioxidant enzymes, should be performed to corroborate this hypothesis.

To date, few studies have described the involvement of antioxidant defence in the response of ticks to pathogen infection. It was previously demonstrated that the glutathione-S-transferase (GST) transcript was induced in IDE8 cells (derived from the tick I. scapularis) in 
response to A. marginale infection [38]. Here, a similar transcriptional profile of Rmgst genes was observed in BME26 cells infected with A. marginale. Importantly, the RNAi-mediated silencing of gst in Dermacentor variabilis caused a reduction of $A$. marginale load in the tick gut after acquisition feeding and in the salivary glands after transmission feeding [38]. In the current study, we have demonstrated that Rmcat, Rmgpx, and Rmtrxr are upregulated up to $72 \mathrm{~h}$ after infection of BME26 cells with $A$. marginale. In addition, we showed that the simultaneous silencing of these three genes decreased the $A$. marginale load, suggesting that they might play an important role in bacterial survival. It has been demonstrated that the viability of B. burgdorferi in I. scapularis salivary glands are affected by the ROS balance [39]. Moreover, the RNAi-mediated silencing of the peroxiredoxin Salp25D decreased the bacterial load in the salivary glands of ticks, suggesting that this protein facilitated the entry of B. burgdorferi. Salp25D is involved in the quenching of extracellular $\mathrm{O}_{2}^{-}$produced by neutrophils, allowing bacterial survival [39]. In addition, we have presented evidence here that the silencing of oxr 1 , which regulates expression of enzymes that detoxify ROS, such as catalase and GPX, led to a reduction in the A. marginale infection. Similar results were demonstrated for A. gambiae infected by $P$. berghei. However, the molecular mechanism of action of oxr1 remains unclear [11].

\section{Conclusions}

Herein, we show that different microbial stimuli trigger distinct gene expression profile of components of the prooxidant/antioxidant system in BME26 cells. Remarkably, A. marginale exposure triggers the downregulation of pro-oxidant genes and the upregulation of antioxidant genes, suggesting that this pathogen might manipulate the oxidative response of BME26 cells to favour bacterial survival towards a more reduced intracellular environment. It is plausible to suppose that the distinct gene profile triggered by $A$. marginale compared with the other microbial challenges evaluated in this study and previous results on immune signalling pathways [17] may be due to the $R$. microplus-A. marginale co-evolution. This coevolutionary scenario may include the adaptation of rickettsial-host interaction to rickettsial advantage, establishing an antioxidant environment and reducing the host immune genes, as well as low rickettsial virulence level, as we observed a low replication rate of $A$. marginale and a high survival of infected BME26 cells. Our results indicate the potential use of BME26 cells to elucidate the molecular mechanisms involved in the infection with $A$. marginale. The mechanisms used by this pathogen to manipulate the immune-triggered production of ROS/RNS are a potential target for the development of new strategies for the control of tick-borne diseases.

\section{Additional file}

Additional file 1: Table S1. Primers used in RT-qPCR analysis and RNAi assays. (DOC $61 \mathrm{~kb}$ )

\section{Abbreviations \\ CAT: Catalase; DUOX: Dual oxidase; ERO1: Endoplasmic reticulum oxidoreductin; GPX: Glutathione peroxidase; GST: Glutathione S-transferase; $\mathrm{H}_{2} \mathrm{O}_{2}$ : Hydrogen peroxide; NO: Nitric oxide; NOS: Nitric oxide synthase; $\mathrm{O}_{2}^{-}$: Superoxide anion; OXR1: Protein oxidation resistance 1; PHGPX: Phospholipid hydroperoxide glutathione peroxidases; PRX: Peroxiredoxin; RNS: Reactive nitrogen species; ROS: Reactive oxygen species; SOD: Superoxide dismutase; TRX: Thioredoxin; TRXR: Thioredoxin reductase}

\section{Acknowledgements}

The authors are grateful to Dr Milton Moraes for microfluidic RTqPCR analysis and Mario Balanco for technical assistance. The gene encoding the merozoite surface protein 1 (MSP1) of Plasmodium falciparum was obtained from a plasmid kindly provided by Dr Gerhard Wunderlich (Institute of Biomedical Sciences, University of São Paulo, Brazil).

\section{Funding}

This research was supported by grants from the São Paulo Research Foundation (FAPESP; Grants 2013/26450-2), National Council for Scientific and Technological Development [CNPq; National Institutes of Science and Technology in Molecular Entomology (INCT-EM)], Coordination for the Improvement of Higher Education Personnel (CAPES). S Kalil and JC Peixoto received doctoral scholarships provided by CNPq (142985/2011-9) and FAPESP (Grants 2011/23549-2), respectively. RDR and PCP were supported by post-doctoral fellowships from CAPES and CNPq, respectively.

Availability of data and materials

All data analysed during this study are included in this published article and in Additional file 1.

\section{Authors' contributions}

SPK, RDR, JCP and PCP designed and performed the high-throughput QPCR experiments. SPK performed other experiments. ACF, RDR and PLO performed the critical revision of the manuscript. SD and ACF contributed with reagents/ materials/analysis tools. SPK and SD wrote the paper. All authors read and approved the final manuscript.

Ethics approval and consent to participate

Not applicable.

Consent for publication

Not applicable.

Competing interests

The authors declare that they have no competing interests.

\section{Publisher's Note}

Springer Nature remains neutral with regard to jurisdictional claims in published maps and institutional affiliations.

\section{Author details}

${ }^{1}$ Department of Parasitology, Institute of Biomedical Sciences, University of São Paulo, São Paulo, São Paulo 05508-900, Brazil. Laboratory of Biochemistry of Hematophagous Arthropods, Institute of Medical Biochemistry Leopoldo de Meis, Federal University of Rio de Janeiro, Rio de Janeiro, Rio de Janeiro 21941-909, Brazil. ${ }^{3}$ Present address: Laboratory of Immunology Applied to Aquaculture, Department of Cell Biology, Embryology, and Genetics, Federal University of Santa Catarina, Florianópolis, Santa Catarina 88040-900, Brazil. 
Received: 10 August 2017 Accepted: 6 December 2017

Published online: 19 December 2017

\section{References}

1. Fang FC. Antimicrobial reactive oxygen and nitrogen species: concepts and controversies. Nat Rev Microbiol. 2004;2(10):820-32.

2. Jones DP. Redefining oxidative stress. Antioxid Redox Signal. 2006;8(9-10): 1865-79.

3. Breitenbach M, Weber M, Rinnerthaler M, Karl T, Breitenbach-Koller L. Oxidative stress in fungi: its function in signal transduction, interaction with plant hosts, and lignocellulose degradation. Biomol Ther. 2015;5(2):318-42.

4. Lambeth JD. NOX enzymes and the biology of reactive oxygen. Nat Rev Immunol. 2004:4(3):181-9.

5. Weidinger A, Kozlov AV. Biological activities of reactive oxygen and nitrogen species: oxidative stress versus signal transduction. Biomol Ther. 2015:5(2):472-84.

6. Rahal A, Kumar A, Singh V, Yadav B, Tiwari R, Chakraborty S, Dhama K. Oxidative stress, prooxidants, and antioxidants: the interplay. Biomed Res Int. 2014:2014:761264.

7. Nakamura H, Nakamura K, Yodoi J. Redox regulation of cellular activation. Annu Rev Immunol. 1997:15:351-69.

8. Navarro-Yepes J, Burns M, Anandhan A, Khalimonchuk O, del Razo LM, Quintanilla-Vega B, et al. Oxidative stress, redox signaling, and autophagy: cell death versus survival. Antioxid Redox Signal. 2014;21(1):66-85.

9. Halliwell B, Gutteridge JMC. Protection against oxidants in biologica systems: the superoxide theory of oxygen toxicity. In: Halliwell B, Gutteridge JMC, editors. Free radicals in biology and medicine. Oxford: Oxford University Press; 1989. p. 86-187.

10. Ha EM, CT O, Bae YS, Lee WJ. A direct role for dual oxidase in Drosophila gut immunity. Science. 2005;310(5749):847-50.

11. Jaramillo-Gutierrez G, Molina-Cruz A, Kumar S, Barillas-Mury C. The Anopheles gambiae oxidation resistance 1 (OXR1) gene regulates expression of enzymes that detoxify reactive oxygen species. PLoS One. 2010;5(6):e11168.

12. Kumar S, Molina-Cruz A, Gupta L, Rodrigues J, Barillas-Mury C. A peroxidase/ dual oxidase system modulates midgut epithelial immunity in Anopheles gambiae. Science. 2010;327(5973):1644-8.

13. Molina-Cruz A, DeJong RJ, Charles B, Gupta L, Kumar S, Jaramillo-Gutierrez G, Barillas-Mury C. Reactive oxygen species modulate Anopheles gambiae immunity against bacteria and Plasmodium. J Biol Chem. 2008;283(6):3217-23.

14. Pereira LS, Oliveira PL, Barja-Fidalgo C, Daffre S. Production of reactive oxygen species by hemocytes from the cattle tick Boophilus microplus. Exp Parasitol. 2001;99(2):66-72.

15. Yang $X$, Smith AA, Williams MS, Pal U. A dityrosine network mediated by dual oxidase and peroxidase influences the persistence of Lyme disease pathogens within the vector. J Biol Chem. 2014;289(18):12813-22.

16. Kocan KM, de la Fuente J, Blouin EF, Coetzee JF, Ewing SA. The natural history of Anaplasma marginale. Vet Parasitol. 2010;167(2-4):95-107.

17. Rosa RD, Capelli-Peixoto J, Mesquita RD, Kalil SP, Pohl PC, Braz GR, et al. Exploring the immune signalling pathway-related genes of the cattle tick Rhipicephalus microplus: from molecular characterization to transcriptional profile upon microbial challenge. Dev Comp Immunol. 2016:59:1-14.

18. Capelli-Peixoto J, Carvalho DD, Johnson WC, Scoles GA, Fogaca AC, Daffre S, Ueti MW. The transcription factor relish controls Anaplasma marginale infection in the bovine tick Rhipicephalus microplus. Dev Comp Immunol. 2017;74:32-9.

19. Esteves E, Lara FA, Lorenzini DM, Costa GH, Fukuzawa AH, Pressinotti LN, et al. Cellular and molecular characterization of an embryonic cell line (BME26) from the tick Rhipicephalus (Boophilus) microplus. Insect Biochem Mol Biol. 2008; 38(5):568-80.

20. Munderloh UG, Liu Y, Wang MM, Chen CS, Kurtti TJ. Establishment, maintenance and description of cell lines from the tick Ixodes scapularis. J Parasitol. 1994;80(4):533-43.

21. de Andrade GM, Machado RZ, Vidotto MC, Vidotto O. Immunization of bovines using a DNA vaccine (pcDNA3.1/MSP1b) prepared from the Jaboticabal strain of Anaplasma marginale. Ann N Y Acad Sci. 2004;1026:257-66.

22. Pinter A, Labruna MB. Isolation of Rickettsia rickettsii and Rickettsia bellii in cell culture from the tick Amblyomma aureolatum in Brazil. Ann N Y Acad Sci. 2006;1078:523-9

23. Bifano TD, Ueti MW, Esteves E, Reif KE, Braz GR, Scoles GA, et al. Knockdown of the Rhipicephalus microplus cytochrome c oxidase subunit III gene is associated with a failure of Anaplasma marginale transmission. PLoS One. 2014;9(5):e98614.
24. Galletti MF, Fujita A, Nishiyama MY, Jr., Malossi CD, Pinter A, Soares JF, et al. Natural blood feeding and temperature shift modulate the global transcriptional profile of Rickettsia rickettsii infecting its tick vector. PLoS One 2013:8(10):e77388

25. Bustin SA, Benes V, Garson JA, Hellemans J, Huggett J, Kubista M, et al. The MIQE guidelines: minimum information for publication of quantitative realtime PCR experiments. Clin Chem. 2009;55(4):611-22.

26. Vandesompele J, De Preter K, Pattyn F, Poppe B, Van Roy N, De Paepe A, Speleman F. Accurate normalization of real-time quantitative RT-PCR data by geometric averaging of multiple internal control genes. Genome Biol. 2002:3(7):RESEARCH0034

27. Esteves E, Bastos CV, Zivkovic Z, de La Fuente J, Kocan K, Blouin E, et al. Propagation of a Brazilian isolate of Anaplasma marginale with appendage in a tick cell line (BME26) derived from Rhipicephalus (Boophilus) microplus. Vet Parasitol. 2009:161(1-2):150-3.

28. Bolton JL, Trush MA, Penning TM, Dryhurst G, Monks TJ. Role of quinones in toxicology. Chem Res Toxicol. 2000;13(3):135-60.

29. Tongul B, Tarhan $L$. The effect of menadione-induced oxidative stress on the in vivo reactive oxygen species and antioxidant response system of Phanerochaete chrysosporium. Process Biochem. 2014;49(2):195-202.

30. Oliveira JH, Goncalves RL, Lara FA, Dias FA, Gandara AC, Menna-Barreto RF, Edwards MC, et al. Blood meal-derived heme decreases ROS levels in the midgut of Aedes aegypti and allows proliferation of intestinal microbiota. PLoS Pathog. 2011:7(3):e1001320.

31. Palmer WJ, Jiggins FM. Comparative genomics reveals the origins and diversity of arthropod immune systems. Mol Biology Evol. 2015:32(8):2111-29.

32. Galletti MF, Fujita A, Rosa RD, Martins LA, Soares HS, Labruna MB, et al. Virulence genes of Rickettsia rickettsii are differentially modulated by either temperature upshift or blood-feeding in tick midgut and salivary glands. Parasit Vectors. 2016;9(1):331

33. Devamanoharan PS, Santucci LA, Hong JE, Tian X, Silverman DJ. Infection of human endothelial cells by Rickettsia rickettsii causes a significant reduction in the levels of key enzymes involved in protection against oxidative injury. Infect Immun. 1994;62(6):2619-21.

34. Santucci LA, Gutierrez PL, Silverman DJ. Rickettsia rickettsii induces superoxide radical and superoxide dismutase in human endothelial cells. Infect Immun. 1992:60(12):5113-8.

35. Rosen GM, Pou S, Ramos CL, Cohen MS, Britigan BE. Free radicals and phagocytic cells. FASEB J. 1995;9(2):200-9.

36. Segal AW. How neutrophils kill microbes. Annu Rev Immunol. 2005;23:197-223.

37. Ryu JH, Ha EM, Lee WJ. Innate immunity and gut-microbe mutualism in Drosophila. Dev Comp Immunol. 2010;34(4):369-76.

38. de la Fuente J, Blouin EF, Manzano-Roman R, Naranjo V, Almazan C, Perez de la Lastra JM, et al. Functional genomic studies of tick cells in response to infection with the cattle pathogen, Anaplasma marginale. Genomics. 2007:90(6):712-22

39. Narasimhan S, Sukumaran B, Bozdogan U, Thomas V, Liang X, DePonte K, et al. A tick antioxidant facilitates the Lyme disease agent's successful migration from the mammalian host to the arthropod vector. Cell Host Microbe. 2007; 2(1):7-18

\section{Submit your next manuscript to BioMed Central and we will help you at every step:}

- We accept pre-submission inquiries

- Our selector tool helps you to find the most relevant journal

- We provide round the clock customer support

- Convenient online submission

- Thorough peer review

- Inclusion in PubMed and all major indexing services

- Maximum visibility for your research

Submit your manuscript at www.biomedcentral.com/submit 